\title{
Re: Superselective Transarterial Chemoembolization as an Alternative to Surgery in Symptomatic/Enlarging Liver Hemangiomas
}

\author{
Jacques Belghiti $^{1}$
}

Published online: 18 July 2017

(C) Société Internationale de Chirurgie 2017

Despite the important technical progress made in liver surgery, restriction of liver resection in patients with harmless lesions is a priority. The extremely low risk of hemangioma rupture should not affect the therapeutic management. Usually, the discovery of an hemangioma should be disregarded, the patients should be reassured, and there is no scientific argument that specific advice regarding any physical activity should be recommended. Similarly, there is no reason to interrupt the use of oral contraceptive or to avoid pregnancy. Finally, no specific follow-up is justified. Surgery remains considered for some giants $(>10 \mathrm{~cm})$ hemangioma clearly associated with discomfort or compression of abdominal adjacent organs. In order to avoid that surgery remains the main complication of hemangioma, there is a serious need to explore alternative treatments such as transarterial chemoembolization, which was described in this study. The inconstant efficiency of hepatic arterial embolization in this vascular lesion has led some authors to dare the adjunction of bleomycin as a sclerosing agent [1]. In the present series, confirming another study from Turkey gathering 26 patients [1], Ozden et al. [2] showed clearly that in "symptomatic" patients with a vast majority of giant hemangiomas, one or two sessions of transarterial chemoembolization were well tolerated and efficient with a $50 \%$ reduction of both lesion volume and improvement in symptoms. This innovative approach requires a prospective study in specialized units collecting possible side effects of this local chemotherapy in non-cancerous patients including the occurrence of pulmonary fibrosis and biliary sclerosing [3]. However, these observations justify to consider this treatment before extensive resection or even liver transplantation in patients with huge hemangioma.

\section{References}

1. Bozkaya H, Cinar C, Besir FH, Parıldar M, Oran I (2014) Minimally invasive treatment of giant haemangiomas of the liver: embolisation with bleomycin. Cardiovasc Intervent Radiol 37(1):101-107. doi:10.1007/s00270-013-0618-y

2. Ozden I, Poyanlı A, Önal Y, Demir AA, Hoş G, Acunaş B (2017) Superselective transarterial chemoembolization as an alternative to surgery in symptomatic/enlarging liver hemangiomas. World $\mathrm{J}$ Surg. doi:10.1007/s00268-017-4069-5

3. O'Sullivan JM, Huddart RA, Norman AR, Nicholls J, Dearnaley DP, Horwich A (2003) Predicting the risk of bleomycin lung toxicity in patients with germ-cell tumours. Ann Oncol 14(1):91-96
Jacques Belghiti

jacques.belghiti@aphp.fr

1 Department of Surgery, Hospital Beaujon, University Paris 7, 92118 Clichy, France 